\title{
Perbaikan Tingkat Kekaburan Gambar Akibat Pembesaran Pada Hasil Screenshot Dengan Metode Unsharp Mask
}

\author{
Soeb Aripin \\ Program Studi Manajemen Teknik Informatika, STMIK Budi Darama, Medan, Indonesia \\ Email: suefarifin@gmail.com
}

\begin{abstract}
Abstrak
Screenshot adalah suatu gambar tampilan yang diambil dari layar monitor seperti perangakat komputer, tablet PC, dan smartphone. Hasil gambar dari screenshot memiliki tingkat ketajaman dan kehalusan yang rendah. Apabila gambar ini diperbesar, maka kulitasnya menjadi rendah seperti blur. Untuk meningkatkan kualitas gambar agar tidak buram pada saat diperbesar, maka proses penajaman dan penghalusan. Proses ini akan meningkatkan kualitas gamba rmenjadi lebih baik. Citra yang diolah dalam penelitian ini gambar hasil screenshot gambar. Selanjutnya citra diolah menggukan pengolahan citra digital menggunakan software Matlab. Tahapan pengolahannya adalah crop, image enhancement dan unsharp mask. Citra hasil image enhancement dan unsharp mask dikolaborasikan untuk memperbesar dan meningkatkan ketajaman dan kehalusan citra pada hasil gambar screenshot yang diuji. Hasil dari pengujian terhadap metode ini dengan kualitas ketajaman lebih baik dengan perbandingan gambar menggunakan mean square error sebanyak 0,0627.2404\%. Citra hasil pengujian telah dapat disimpulkan bahwa nilai pixel-pixel yang dicari memiliki ukuran citra lebih besar dari aslinya serta memiliki resolusi yang lebih besar dari citra awal dan ketajaman dan kehalusan sehinga metode unsharp mask dapat meningkatkan ketajaman dan kehalusan gambar. Namun perubahan yang dihasilkan dengan menggunakan metode belum cukup signifikan.
\end{abstract}

Kata Kunci: Screenshot, Citra, Enhancement Image, Unsharp Mask

\begin{abstract}
Screenshot is a display image taken from a monitor screen such as computers, tablet PCs and smartphones. The image results from the screenshot have a low level of sharpness and smoothness. If this image is enlarged, the quality becomes low like blur. To improve the quality of the image so that it is not blurred when enlarged, then the process of sharpening and smoothing. This process will improve the quality of the image to be better. The image that is processed in this research is the image screenshot. Furthermore, the image is processed using digital image processing using Matlab software. The processing stages are crop, image enhancement and unsharp mask. The image of the image enhancement and unsharp mask results are collaborated to increase and increase the sharpness and smoothness of the image in the results of the screenshot image being tested. The results of testing on this method with better sharpness quality with a comparison of images using the mean square error of $0.0627 .2404 \%$. The image of the test results can be concluded that the value of the pixels sought has a larger image size than the original and has a resolution greater than the initial image and sharpness and smoothness so that the unsharp mask method can improve the sharpness and smoothness of the image. But the changes produced using the method have not been significant enough.
\end{abstract}

Keywords: Screenshot, Image, Enhancement Image, Unsharp Mask

\section{PENDAHULUAN}

Suatu gambar tampilan yang diambil dari layar monitor seperti perangkat komputer, tablet PC dan smartphone adalah screenshot. Hasil gambar dari screenshot memiliki kehalusan dan tingkat ketajaman citra yang kecil, sehingga mendapatkan citra yang lebih baik dapat dilakukan pembesaran terhadap citra tersebut secara langsung (Aripin dan Sunandar, 2017). Dalam pengolahan berbagai jenis citra, yang merupakan salah satu bidang yang cukup populer hingga saat ini, seperti perbaikan kualitas citra (image enhancement). Dengan menggunakan image enhancement, penajaman citra sangat diperlukan agar seseorang dapat melihat dan mengamati citra dengan jelas tanpa adanya halanga dan gangguan. Suatu citra dapat mengalami gangguan yang berupa kerusakan pada beberapa bagian/blok pixel pada proses pengiriman/transmisi atau proses penyimpanan [1]. Kerusakan ini adalah bentuk kesalahan yang utama pada suatu citra, misalnya citra hasil screenshoot.

Salah satu tolak ukur yang utama dalam pemrosesan citra digital untuk mencari informasi dari citra berdasarkan warna dan ketajaman merupakan tingkat ketajaman dan kehalusan citra [2]. Berbagai metode dalam perbaikan citra untuk melakukan ketajaman dan kehalusan citra yang digunkan adalah metode unsharp mask[3][4][5]. Salah teknik yang digunakan untuk mempertajam suatu citra berdasarkan tingkat blur gambar adalah metode unsharp mask[4][6].

Dalam penelitian ini, memiliki masukan data, berupa gambar yang memiliki informasi keluaran pada proses perbaikan daerah digital citra yang pixel nya kosong (tampak pecah-pecah atau kasar). Nilai kekosongan ini juga tergantung pada nilai kali pembesaran. Mengatasi masalah tersebut perlu dilakukan langkah-langkah perbaikan kualitas gambar untuk mengatasi tingkat kekaburan gambar. Citra yang diolah dalam penelitian ini gambar hasil screenshot. Selanjutnya citra diolah menggunakan pengolahan citra digital dengan software Matlab R2010a. Tahapan pengolahannya adalah crop, image enhancement dan unsharp mask. Citra hasil image enhancement dan unsharp mask dikolaborasikan untuk memperbesar dan meningkatkan kehalusan dan ketajaman citra pada hasil gambar screenshot yang diuji. Penelitian sebelumnya telah dilakukan untuk perbaikan gambar hasil screenshot.[7] melakukan penelitian untuk perbaikan citra pada hasil screenshot dengan perosesan pada saat 
pembesaran menggunakan metode interpolasi linier. [8] Melakukan penelitian untuk meningkatkan kecerahan citra pada hasil gambar screenshot menggunakan metode retinex.

Pada penelitian ini, digunkan sebuah metode pengolahan citra digital dalam meperbaikin citra hasil gambar scrennshot yang telah diperbesar dengan menggunkan teknik pengurangan tingkat blur yang dimiliki gambar yaitu metode unsharp mask. Hasil dari pengujian terhadap metode unsharp mask untuk kualitas ketajaman lebih baik dengan perbandingan gambar menggunakan mean square error. Untuk mengetahui tingkat dari perbaikan citra yang diolah, sehingga tingkat perbaikanya dapat diketahui sehinga metode unsharp mask dapat meningkatkan ketajaman dan kehalusan gambar.

\section{TEORITIS}

\subsection{Screenshot}

Screenshot atau screen capture dibutuhkan saat anda ingin mendokumentasikan segala sesuatu yang tampak pada layer monitor jendela komputer kedalam image yang pasip [9]. Printscreen atau screenshot berfungsi untuk menangkap gambar layar hanphone, sehingga dapat dipakai untuk mendokumentasi atau kebutuhan lain yang sering di sebut mobile printscree. Berdasarkan pengertian di atas penulis dapat mengambil kesimpulan bahwa screenshot adalah suatu dokumentasi gambar tampilan yang diambil dari layar monitor seperti perangakat komputer, tablet PC dan smartphone. Penggunaan gambar screenshot biasanya dijadikan sebagai bukti otentik bahwa suatu pihak sudah pernah mengeluarkan pernyataan atau informasi tertentu. Informasi dari isi screenshot biasanya memuat dari gambar atau teks. Hasil dari gambar sreenshot memiliki ukuran yang sama dengan ukuran layar monitor seperti perangakat komputer, tablet PC dan smartphone. Proses penyeleksian terhada hasil gambar screenshot biasanya diambil beberapa potongan gambar yang dijadikan sebagai sampel.

\subsection{Penjualan}

Unsharp mask merupakan salah satu metode pemrosesan citra digital yang dapat digunakan untuk mengurangi tingkat kekaburan citra yang disebabkan oleh camera shake. Penamaan kata Unsharp dikarenakan metode ini menggunakan citra yang lebih blur terhadap citra asli sebagai faktor pembuat mask. Setelah didapatkan mask, maka mask tersebut akan dijumlahkan dengan citra asli sehingga didapatkan keadaan citra yang lebih tajam dibandingkan citra asli. The "Unsharp" dari nama tersebut berasal dari fakta bahwa teknik ini menggunakan kabur, atau "Unsharp," positif untuk menciptakan sebuah "topeng" dari gambar asli. Topeng Unsharped kemudian dikombinasikan dengan negatif, menciptakan ilusi bahwa gambar yang dihasilkan lebih tajam daripada yang asli. Dari pengolahan citra sudut pandang, sebuah topeng Unsharp umumnya linier atau nonlinier filter yang menguatkan frekuensi tinggi komponen[9].

Adapun proses penyelesaian dapat dilakukan dengan menggunakan rumus :

$$
(I * F)(x, y)=\sum_{s=-a t}^{a} \sum_{b}^{a} F(s, t) I(x+s, y+t)
$$

di mana :

$$
\begin{array}{ll}
\mathrm{a} & =(\mathrm{m}-1) / 2 \\
\mathrm{~b} & =(\mathrm{n}-1) / 2 \\
\mathrm{~m}, \mathrm{n} & =\text { ukuran panjang, lebar filter }
\end{array}
$$

Adapu rumus pembuatan unsharp seperti di bawah ini:

$$
\begin{aligned}
& \mathrm{G}(\mathrm{x}, \mathrm{y})=f(x, y)-f_{\text {smooth }}(x, y) \\
& M(x, y)=I(x, y)-G(x, y) \ldots \ldots
\end{aligned}
$$

Dibanding dengan metode menggunakan dekonvolusi, Unsharp mask melakukan proses yang berbeda dimana pada Unsharp mask tidak dibutuhkan informasi penyebab kekaburan citra. Dekonvolusi membutuhkan informasi penyebab kekaburan citra sebagai dasar proses perbaikan. Hal ini menyebabkan terdapat perbedaan mencolok pada waktu persiapan dan pemrosesan citra antara ke dua metode. Unsharp mask menggunakan waktu yang relatif lebih cepat dalam pemrosesannya, sedangkan dekonvolusi membutuhkan waktu yang lebih lama.

\section{ANALISA DAN PEMBAHASAN}

Peningkatan kualitas citra adalah suatu proses untuk mengubah sebuah citra menjadi citra yang baru sesuai dengan kebutuhan melalui berbagai cara seperti dengan fungsi transformasi, operasi matematis dan pemfilteran. Peningkatan kualitas diperlukan karena seringkali citra yang dijadikan objek pembahasan mempunyai kualitas yang buruk, misalnya citra mengalami derau (noise) pada saat pengiriman melalui saluran transmisi, citra terlalu terang/gelap, citra kurang tajam, kabur dan sebagainya. Proses Peningkatan kualitas citra dapat dilakukan dengan menerapkan berbagai metode untuk menghasilkan citra yang lebih bagus dari citra sebelumnya salah satunya yaitu metode pemfilteran. Tujuan atama dari peningkatan kualitas citra ini adalah untuk memproses citra sesuai citra yang dihasilkan lebih baik dari citra aslinya. 
Berikut ini merupakan data citra hasil screenshot yang diperoleh dari screenshot PC komputer dan laptop sesuai dengan format dan resolusi masing-masing citra seperti pada table 1 di bawah ini:

Tabel 1. Data Citra Hasil Screenshot

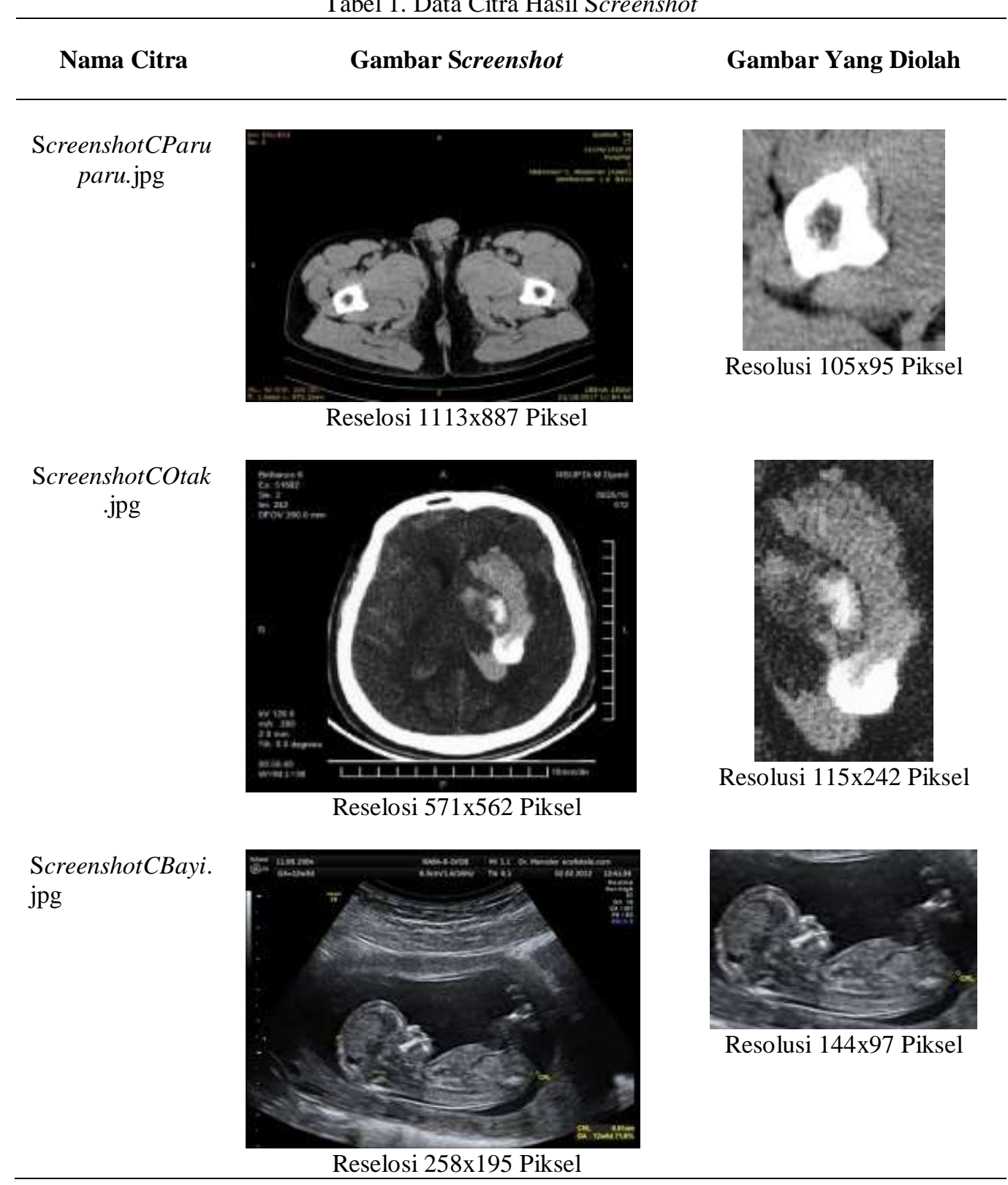

Unsharp mask merupakan salah satu metode pemrosesan citra digital yang dapat digunakan untuk mengurangi tingkat kekaburan citra yang disebabkan oleh camera shake. Penamaan kata Unsharp dikarenakan metode ini menggunakan citra yang lebih blur terhadap citra asli sebagai faktor pembuat mask. Setelah didapatkan mask, maka mask tersebut akan dijumlahkan dengan citra asli sehingga didapatkan keadaan citra yang lebih tajam dibandingkan citra asli.

Adapun algoritma perbaikan tingkat kekaburan gambar akibat pembesaran pada hasil screenshot dapat dilihat dalam ilustrasi diagram alir sistem di bawah ini :

Algoritma proses mengurangi tingkat kekaburan citra dengan unsharp mask

1. Hasil Screenshot

2. Proses seleksi atau crop citra input

3. Proses Pembesaran

4. Hasil Pembesaran

5. Proses Unsharp Mask

a. Pembuatan Gambar Blur dengan Konvolusi Gaussian Filter

b. Hasil Blur Citra

c. Proses Pembuatan Unsharp Mask

d. Hasil Unsharp Mask 
Adapun proses dari algoritma diatas adalah seperti berikut ini:

1. Hasil screenshot

Data di dapatkan dengan cara melakukan screenshot gambar aicon tombol seperti gambar 1. di bawah ini.

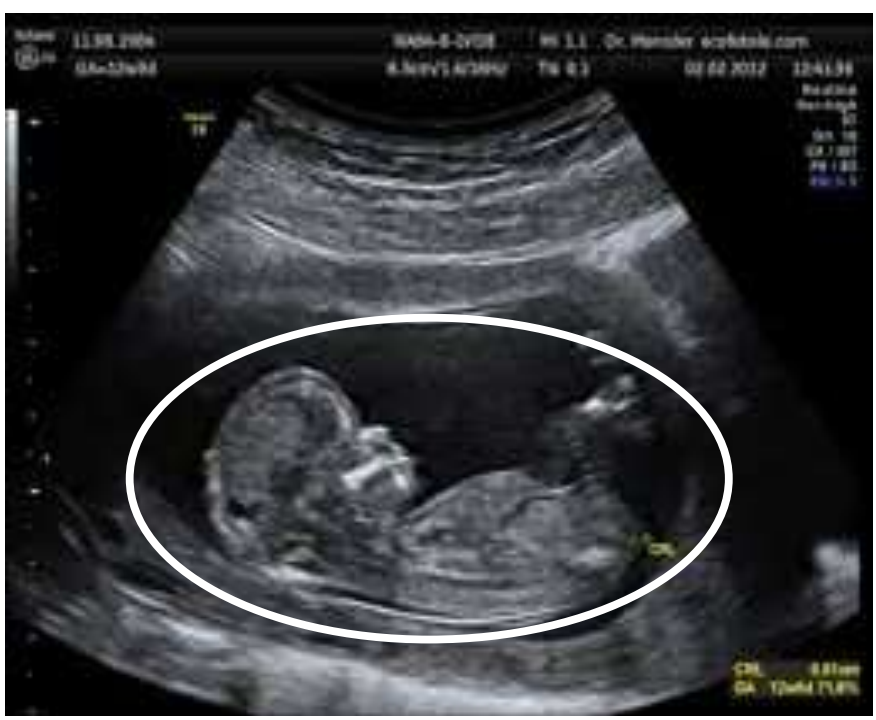

Gambar 1. Hasil Screenshot1

2. Proses seleksi atau crop citra input

Setelah itu melakukan seleksi gambar atau croping dimana gambar yang diseleksi pada objek yang dilingkari hitam pada gambar 2 seperti dibawah ini.

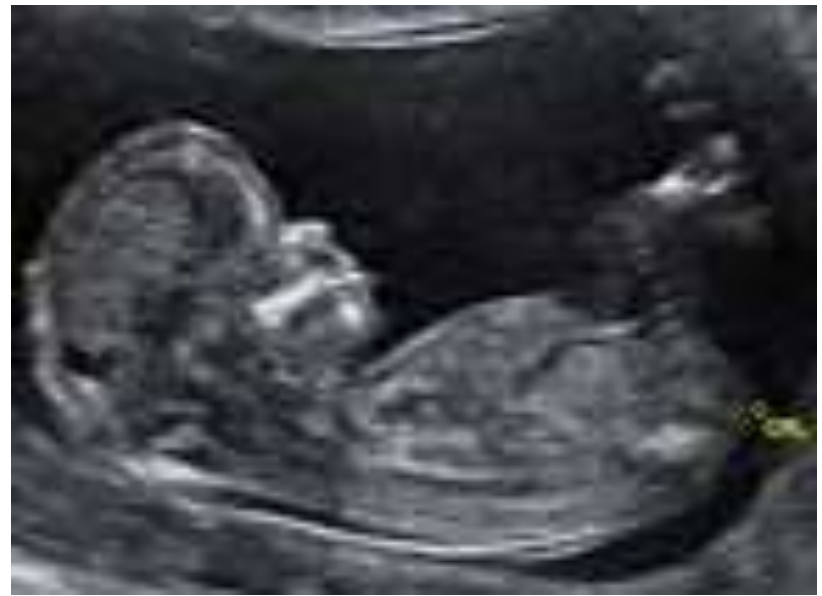

Gambar 2. Hasil Crop Dengan ukuran 144x97 Piksel

3. Proses Pembesaran

Proses selanjutnya melakukan pembesaran citra hasil Crop pada gambar 2. di bawah ini. Dengan menggunakan algoritma interpolation biliner pada aplikasi Matlab adapun perintah fungsi matlabnya adalah sebagai berikut:

$f(x, y)=\sum_{i, j=0}^{N=1} a_{i, j} x^{i} y^{j}$

$\mathrm{I}=$ imread('screenshot1,jpg');

$\mathrm{J}=$ imresize(I, [100 150],'bilinear');

Figure imshowpair(I,J,'montage')

axis off

4. Hasi pembesaran

Dari proses diatas didapatkan hasil pembesarnya dari citra hasil crop screenshot adalah seperti gambar 4 . dibawah ini: 


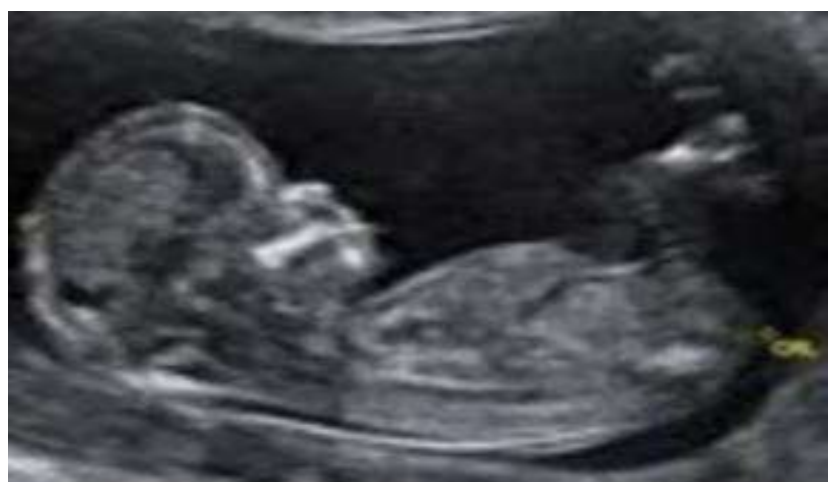

Gambar 3. Hasil Pembesaran Dengan Ukuran 287x193 Pixsel

5. Proses Unsharp Mask

Selanjutnya melakukan opera proses unsharp mask dengan cara menambahkan hasil konvulasi dengan citra awal untuk mendapatkan citra Unsharp Mask dengan mengunkan rumus sebagai berikut:

$$
\begin{aligned}
& (I * F)(x, y)=\sum_{s=-a t}^{a} \sum_{b}^{a} F(s, t) I(x+s, y+t) \\
& \mathrm{g}(\mathrm{x}, \mathrm{y})=f(x, y)-f_{\text {smooth }}(x, y)
\end{aligned}
$$

Jadi secara umum rumus diatas adalah jumlah pengurangan antara pixel citra asli dengan filter hasil konvulusi dan hasilnya dari matriks konvulusi $3 \times 3$. Untuk penjelasan proses penjumlahan hanya di lakukan pada nilai yang telah di konvolusi pada hasil mask adapun prosesnya sebagai berikut ini:
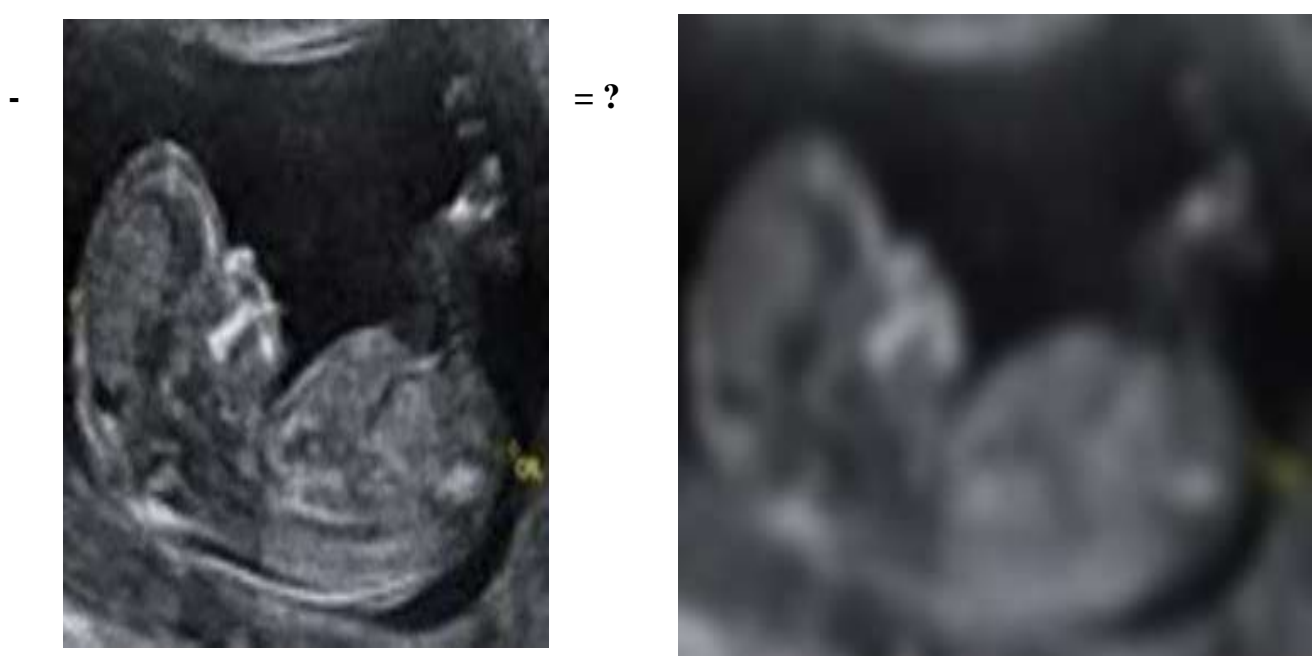

Gambar 4. Proses Metode Unsharp Mask

Sehingga hasil dari proses metode unsharp mask adalah sebagai berikut :
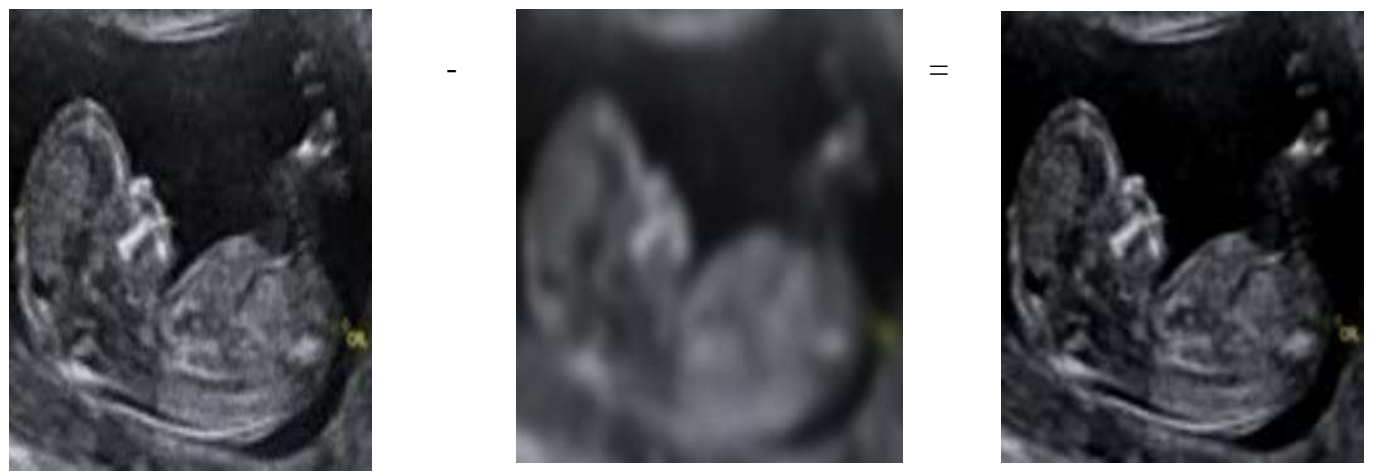

Gambar 5. Hasil Metode Unsharp Mask

\section{IMPLEMENTASI}

Penelitian ini menggunakan sampel sebanyak 3 buah citra screenshot yang diperoleh dari PC laptop. Hasil pengujian ini sehingga dihasilkan citra yang memiliki kualitas lebih bagus dari kualitas citra sebelumnya. Hasil 
pengujian citra input perbaikan tingkat kekaburan gambar hasi screenshot menggunakan metode unsharp mask dapat dilihat pada tabel 2 .

Tabel 2. Pengujian Citra hasil screenshot dengan Unsharp Mask
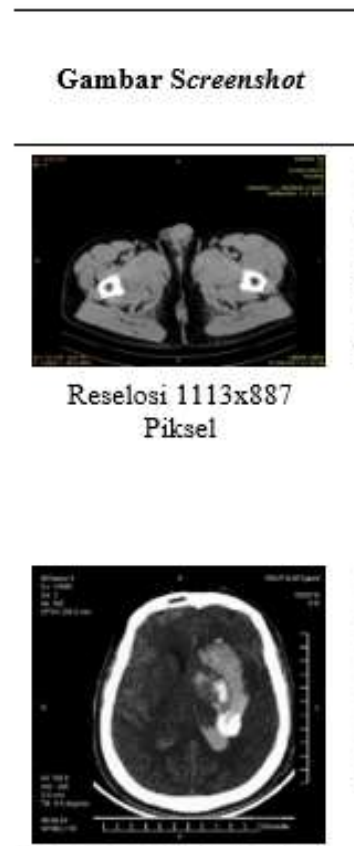

Reselosi 1366x768 Piksel

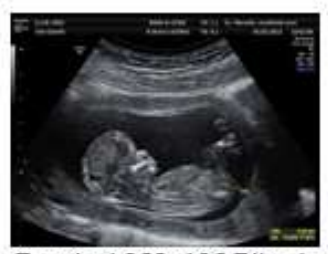

Reselosi 258x195 Piksel

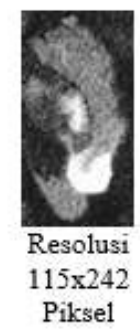

\begin{tabular}{cc}
$\begin{array}{c}\text { Gambar } \\
\text { Hasil } \\
\text { Crop }\end{array}$ & $\begin{array}{c}\text { Gambar } \\
\text { Hasil } \\
\text { Pembesaran }\end{array}$ \\
\hline & \\
\hline
\end{tabular}

Piksel

Resolusi

$405 \times 375$

Piksel

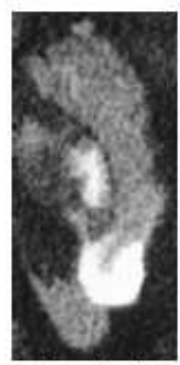

Resolusi

$229 \times 483$

Piksel

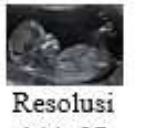

Piksel

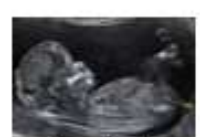

Resolusi

$287 \times 193$

Piksel

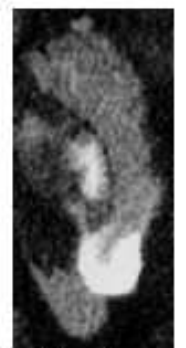

Resolusi 140x140 Piksel

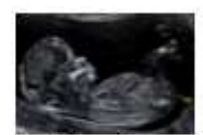

Resolusi $140 \times 140$ Piksel

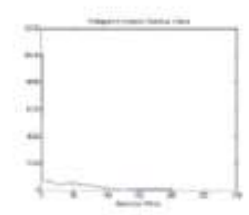

Kesimpulan dari tingkat kecerahan warna antara citra gambar hasil pembesaran yaitu $0 \mathrm{~s} / \mathrm{d} 205$ piksel dan hasil unsharp mask tingkat kecerahan warna antara $0 \mathrm{~s} / \mathrm{d} 183$ piksel dengan nilai $\mathrm{MSE}=0,0576.3935 \%$

\section{KESIMPULAN}

Penulis mencoba menarik kesimpulan dari pembahasan sebelumnya yaitu :

1. Proses perbaikan tingkat kekaburan gambar hasi screenshot dilakukan dengan tiga tahap. Pada tahap pertama terlebih dahulu dilakukan proses seleksi citra, tahap kedua proses pembesaran citra dan tahap ke tiga dengan menerapkan metode unsharp mask untuk meningkatkan kualitas citra hasil pembesaran tersebut sehingga meningkatkan resolusi ketajaman citra tersebut.

2. Metode unsharp mask dapat diterapkan dalam perbaikan tingkat kekaburan gambar hasi screenshot dengan cara membuat gambar yang lebih blur mask dengan proses konvolusi metode filter gaussian untuk perbandingan citra dengan citra awal yang selanjutnya mendapatkan citra unsharp mask yang memiliki citra yang lebih tingkat kecerahan lebih baik.

3. Implementasi perbaikan tingkat kekaburan gambar hasi screenshot dengan unsharp mask dengan menggunakan GUI Matlab 2010a dan dapat dijalankan pada sistem operasi windows dan telah dapat melakukan proses perbaikan tingkat kekaburan gambar hasi screenshot sehingga dihasilkan citra yang lebih baik.

\section{REFERENCES}

[1] Kwok, N. M., Shi, H. Y., Fang, G. and Ha, Q. P. (2012) "Intensity-based gain adaptive unsharp masking for image contrast enhancement", in 2012 5th International Congress on Image and Signal Processing, CISP 2012, pp. 529-533. doi: 10.1109/CISP.2012.6469772. 
[2] Lin, S. C. F., Wong, C. Y., Jiang, G., Rahman, M. A., Ren, T. R., Kwok, N., Shi, H., Yu, Y. H. and Wu, T. (2016) "Intensity and edge based adaptive unsharp masking filter for color image enhancement", Optik, 127(1), pp. 407-414. doi: 10.1016/j.ijleo.2015.08.046.

[3] Hari, V. S., Jagathy Raj, V. P. and Gopikakumari, R. (2013) "Unsharp masking using quadratic filter for the enhancement of fingerprints in noisy background", Pattern Recognition, 46(12), pp. 3198-3207. doi: 10.1016/j.patcog.2013.05.014.

[4] Kim, D. H. and Ye, S. Y. (2014) "CAD for detection of brain tumor using the symmetry contribution from MR image applying unsharp mask filter", Transactions on Electrical and Electronic Materials, 15(4), pp. 230-234. doi: 10.4313/TEEM.2014.15.4.230.

[5] Afshari, H H, S A Gadsden, and S Habibi (2017). "Signal Processing Gaussian Filters for Parameter and State Estimation". HIm. 3639

[6] Kuş, P. and Karagöz, I. (2013) "Detection of microcalcification clusters in digitized X-ray mammograms using unsharp masking and image statistics", Turkish Journal of Electrical Engineering and Computer Sciences, 21(SUPPL. 1), pp. 2048-2061. doi: 10.3906.

[7] Aripin, S., Ginting, G. L. and Silalahi, N. (2017) "Penerapan metode retinex untuk meningkatkan kecerahan citra pada hasil screenshot", MEDIA INFORMATIKA BUDIDARMA, 1(1), pp. 24-27.

[8] Aripin, S. and Sunandar, H. (2017) "Perancangan aplikasi perbaikan citra pada hasil screenshot menggunakan metode interpolasi linier",PELITA 16(1), pp. 51-58.

[9] Pelliccia, D., Paganin, D. M. and Garbe, U. (2015) "Physical unsharp mask with structured detection", Optics Letters, 40(15), p. 3611. doi: 10.1364/OL.40.003611.

[10] Zhao, Z. and Zhou, Y. (2016) "PLIP based unsharp masking for medical image enhancement", in ICASSP, IEEE International Conference on Acoustics, Speech and Signal Processing - Proceedings, pp. 1238-1242. doi: 10.1109/ICASSP.2016.7471874.

[11] Komputer, Wahana (2004). Teknik Pengolahan Citra. Yogyakarta: Andi.

[12] Putra, Darma (2012). Pengolahan Citra Digital. Yogyakarta: Andi.

[13] Sasongko, Setia Budi (2010). Metode Numrik Dengan Scilab. Yogyakarta: Andi.

[14] Supardi, Yuniar (2009). Aplikasi Populer Handphone. Jakarta: PT. Gramedia.

[15] Sutoyo, T, Edy Mulyanto, Vincent Suhartono, Oky Dwi Nurhayati, and M T Wijanarto (2009). Teori Pengolahan Citra Digital. Yogyakarta: Andi.

[16] Usman, Nurdin (2002). Konteks Implementasi Berbasi Kurikulum. Jakarta: PT. Raja Grafindo Persada. 